\title{
Dorset Site Variation on the Southeast Coast of Baffin Island
}

\author{
MOREAU S. MAXWELL'
}

\begin{abstract}
The wide variation in Dorset residence structures may indicate seasonal site differences greater than a simple summer/ winter dichotomy. This is further suggested by a comparison of selected stone tool frequencies from Dorset sites near Lake Harbour, N.W.T. Here manufacturing activities appear to differ from spring to summer to winter. The evidence also suggests that in this region Late Dorset winter settlements were located on the fast sea ice.
\end{abstract}

RÉSUMÉ. La grande variation de structure dans les residences d'age Dorset, peut indiquer les différences de site saisonier plus importantes que celles du passage de l'hiver à l'été. Cela est de loin suggèré par une comparaison dans la frequénce d'outils en pierre sélectionés, provenant de sites d'age Dorset aux alentours de Lake Harbour - N.W.T. Là, les activites artisanales apparaissent changer du printemps à l'été puis à l'hiver. Dans cette region, il parait evident que les colonies hivernales d'age Dorset terminal se placaient sur la glace de mer immobilisée.

Traduit par Alain de Vendegies, Aquitaine Company of Canada Ltd.

\section{INTRODUCTION}

Through the past 52 years of Dorset studies less attention has been paid to settlement systems than to inter-site comparisons of artifact complexes. This is partly due to the general nature of Dorset artifacts. They differ distinctively from those of other Arctic cultural periods and within specific categories they tend to be stylistically similar over a broad area. Artifact styles appear to conform nearly simultaneously at specific points in time. But this patterned conformity seems surprisingly absent when settlement systems, and particularly residence structures, are viewed across Dorset time and space. The rock, soil, and artifact concentrations we have interpreted as Dorset shelters vary widely by region and period within the Dorset sphere (Cf. Harp, 1976; Mary-Rousselière, 1976; Plumet, 1976, 1979; Schledermann, 1978; Wenzel, 1979).

On the southeast coast of Baffin Island, Thule and modern "camp" Inuit have left observable evidence of a settlement system that incorporates the structures and loci of activity utilized by single bands through at least one annual cycle (Maxwell, 1979). Components of this system are: semi-permanent qarmats or pithouses, summer skin or canvas tents, hunting and foraging arenas that include fish weirs and fox traps, butchering sites for large sea mammals, rock meat caches, graves and navigation markers (inuksuk). This logically adaptive complex occurs repeatedly along the eastern arctic coast and counterparts to these recent features probably occurred in Dorset times. However, in our research area, covering more than $500 \mathrm{~km}$ of coast and many more $\mathrm{km}$ of coastline, we have had great difficulty in identifying Dorset residence structures, let alone the season of their use. 
Several factors contribute to this difficulty. This coast is wet and in many spots has a thick sod mantle. None of the many Dorset sites located showed any surface trace of the cultural material beneath; all were identified only by shovel testing on likely flat terrain. Since there are relatively few tent-sized flat areas along this steep, rocky coast, a situation compounded by a twice-daily tidal fluctuation of 9 to $12 \mathrm{~m}$, most potential sites within the research area have been tested. In a few cases favorable occupation loci were periodically re-used for one or two centuries, creating a reshuffled confusion of rocks and mixture of artifacts. But only the Nanook site (Arundale, 1976), $12 \mathrm{~m}$ above highest tide, was sporadically occupied for as long as five centuries. In general the Dorset sites have been close to coeval sea levels, proceeding downgrade through time as sea levels declined. Even accounting for the re-use of the same rocks to hold down a century of skin roofs, there appear to have been too few residence structures for the population. Taking several factors into consideration, I have suggested (Maxwell, 1979) that at any point in time the Dorset population along this coast was between 100 and 200 persons. Even using minimal numbers such as a 100-person population renewed every 30 years over a 1500 -year span, a total winter housing requirement for 5000 persons would have existed. Nothing in the southeastern Baffin Island evidence indicates a fraction of these required houses. This suggests that much of the winter was spent in snow houses, probably on fast ice.

\section{Residence Form Variation}

Summarizing the range of Dorset residence structure variation throughout the Eastern Arctic helps to put this problem into perspective. Disregarding those jumbles of rock and artifact concentrations which excavators have been unable to interpret, there are at least 10 to 20 variants of Dorset housing, depending on the level at which one distinguishes varieties. The most distinctive of these are variants of what have been called "mid-passage" or axial structures (for example: Cox, 1978:110). They are distinguished by central linear features which usually run perpendicular to the nearest body of water. These axial structures may be on an extant surface or in a pit; the linear feature may be parallel rows of vertical slabs incorporating box hearths, or it may be a trench and hearth, or a mosaic pavement. The outer configuration may be round, oval or rectangular, and the perimeter, often a low gravel ridge, may not be clearly delineated. Axial structures, and particularly pit structures, have generally been interpreted as winter houses.

Additionally, there are varieties of pit houses without central axial features, tent platforms in a wide range of shapes and sizes with and without axial features, surface structures built only of sod blocks, and "long houses" with and without indications of multi-family residences (for examples see: Plumet, 1976:200; Schledermann, 1978:466). This cultural trait of combined axial features and vertical stone slabs appears in Early Pre-Dorset and/or Independence I; in several Eastern Arctic regions it continues through a number of early and developed Dorset phases until at least A.D. 1400 (Harp, 1976; Cox, 1978). This 
trait appears to be particularly common in Late Dorset. However, the trait has surprisingly not been reported and appears not to be present from the Dorset Core Area at Pond Inlet, Igloolik, Southampton Island, Sugluk, and southeastern Baffin Island. It is significant that at some 40 Dorset sites located in southeastern Baffin there is not a single vertically placed slab. Extensive use of rock slabs by later Thule people indicate that this cannot be attributed to lack of suitable material.

The distribution of axial features and vertical slabs is less critical to the points of this paper than is the wide variety of house styles. This variety suggests not only differentiation between summer and winter dwellings but perhaps other seasonal variants as well. It follows that the cultural residue within these seasonal variants should also reflect slight variations in hunting and household activities. In the inter-site comparison of artifact complexes, therefore, there may be danger in equating site 1 from region $A$ with site 2 from region $B$ if the two sites were used in different seasons of the year.

\section{Dorset Site Variation, Southeastern Baffin Island}

Even though there is scanty evidence of southeastern Baffin residence structures, house type in a few instances is reasonably clear. Clearest of these is a portion of the Early Dorset Morrisson site (KdDq-7-3) (Fig. 1). The structure is a small oval pit house $46 \mathrm{~cm}$ deep with a sleeping bench $1 \mathrm{~m}$ wide built of several

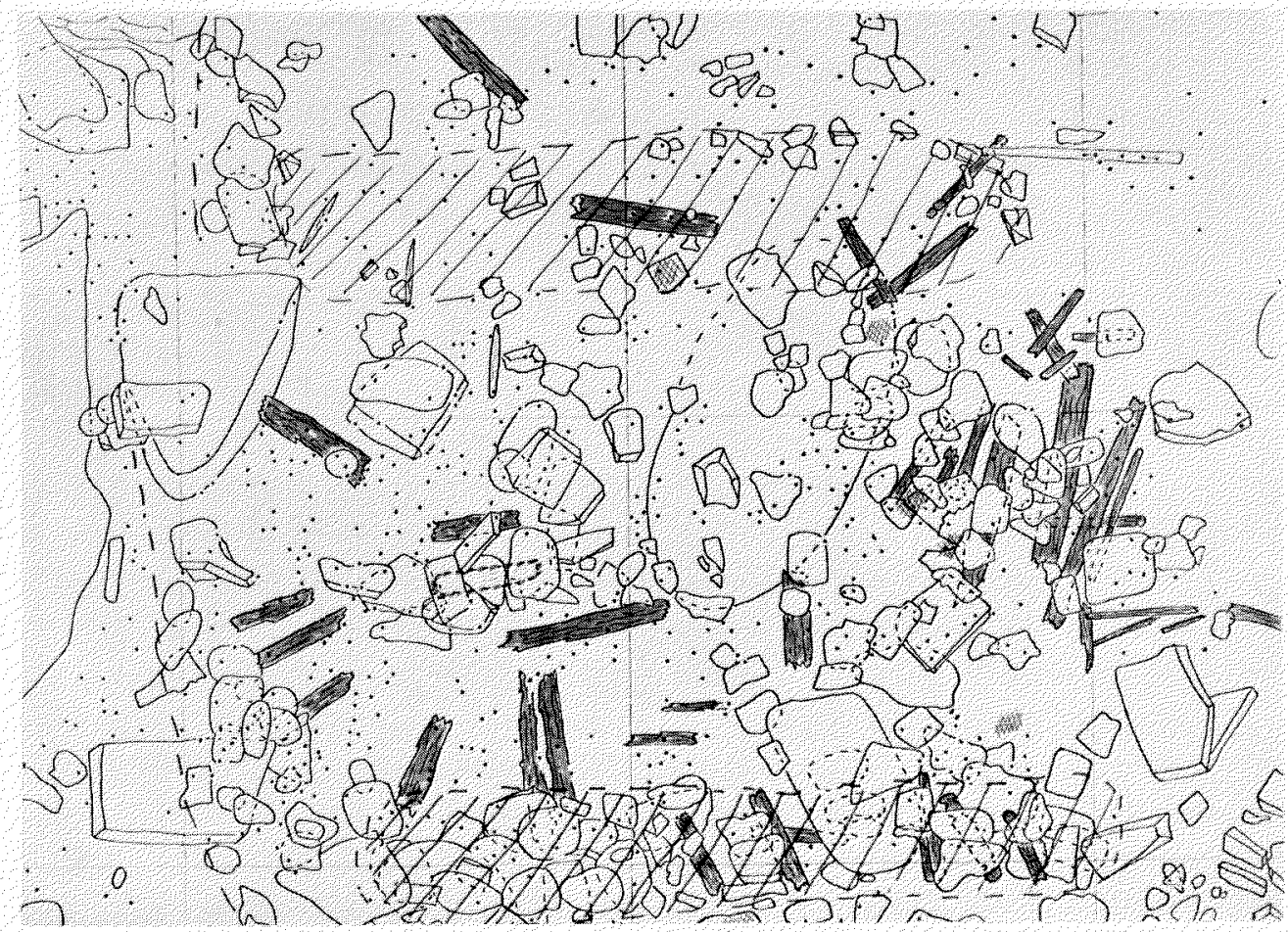

FIG. 1. Pit house with driftwood roof supports, Morrisson site (KdDq-7-3). 
rock courses along one long side. The opposite side appears to have a gravelbased sleeping bench. Driftwood sticks held up the roof, and five small cooking areas were arranged around the floor perimeter. A large glacial erratic or bedrock exposure covered with angular rocks dominated the central pit, but this was not used as a hearth and the angular rocks appear to have been placed there after the pit house was abandoned. Bones from small seals constitute $80 \%$ of the faunal sample, but a slightly higher percentage of square flipper seal and walrus bones than found in other sites suggests more hunting along the winter floe edge. House form, faunal assemblage, and such artifacts as sled shoes and ice creepers thus indicate that this is a winter residence.

Summer camping in the valley where the Morrisson site is located is uncomfortable to say the least after the thick, damp moss has thawed. Virtually opposite soil surface conditions exist at the Crystal II site near the town of Frobisher Bay. Here the thin, well-drained soil mantle provides a comfortable

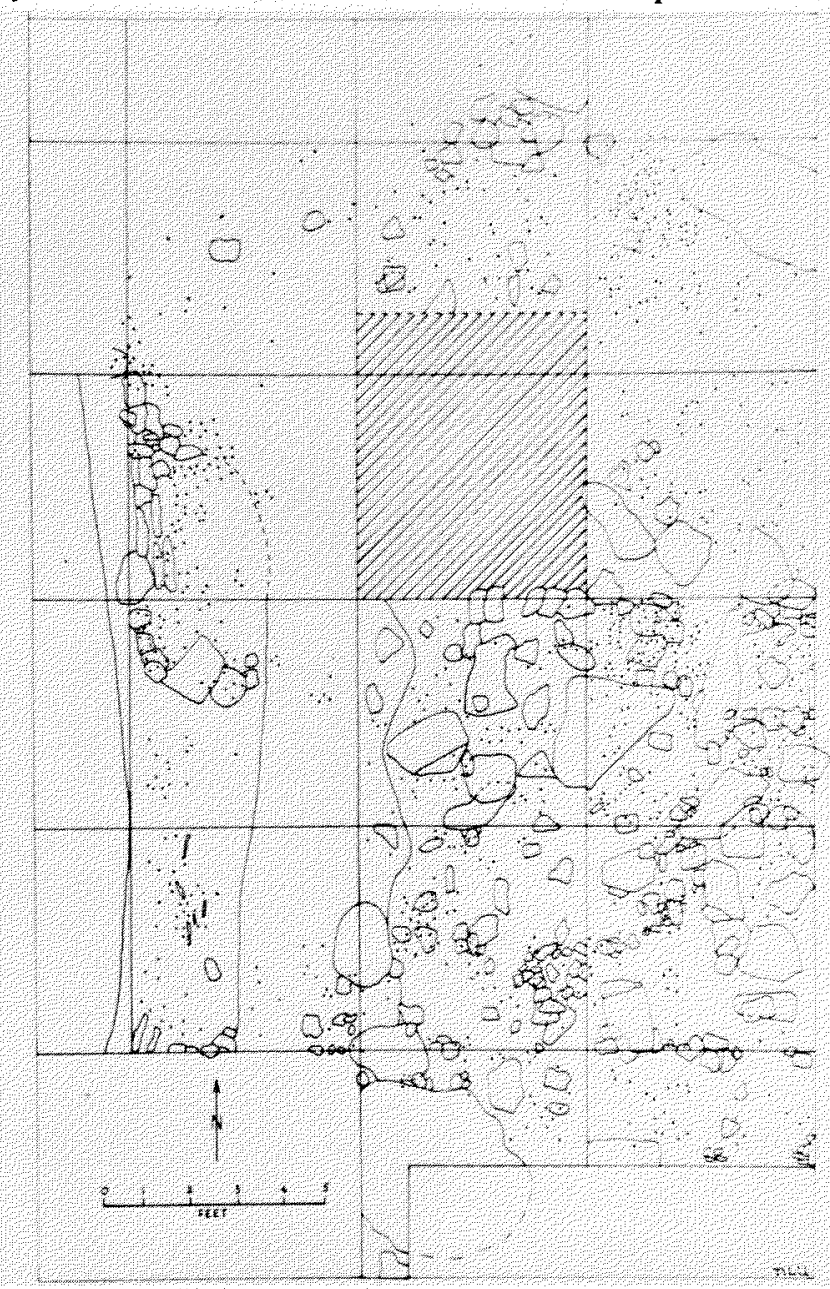

FIG. 2. Main body of Crystal II site (KkDn-1). 
summer camp. It is situated $2 \mathrm{~km}$ inland on a tidal river and is ecologically desirable only because it is adjacent to one of the best char fishing rivers in southeastern Baffin Island. The main body of the site is an indecipherable array of re-shuffled rocks (Fig. 2), but $3 \mathrm{~m}$ to the north is an isolated rectangular configuration of rocks best interpreted as hold-downs for a summer tent. The 88 lithic artifacts clustering around and within this rock configuration are stylistically indistinguishable from the main body of the site, suggesting that the whole site was used for summer camping. Although we have no radiocarbon dates for the site, the style of its artifacts and its location, barely $4 \mathrm{~m}$ above highest tide, suggest a Late Dorset occupation contemporaneous with the Abverdjar site near Igloolik (Rowley, 1940) at an estimated date of A.D. 500 to 800 .

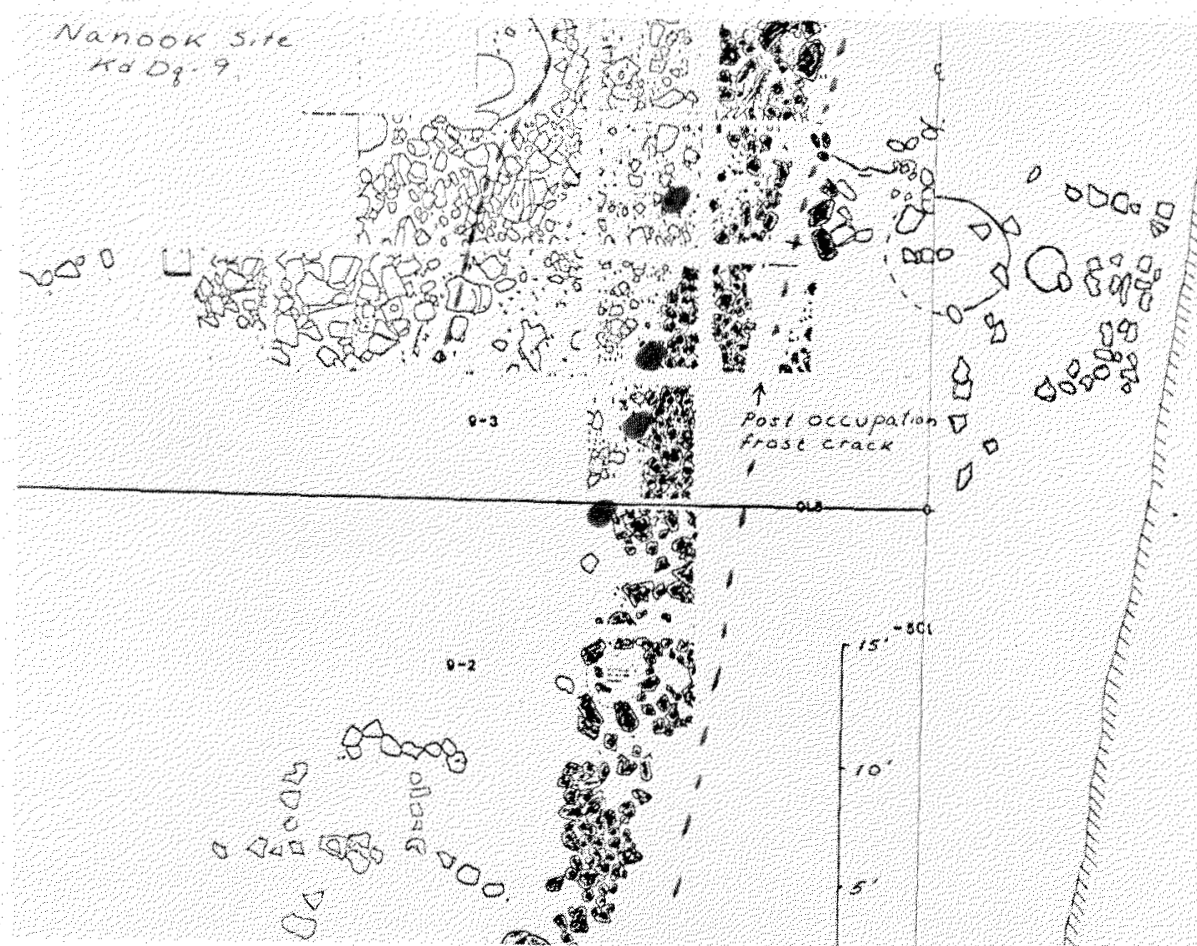

FIG. 3. Nanook site (KdDq-9). Four cooking areas are indicated to the lett of the rock and sou sleeping bench (?).

The third site for consideration here is the Nanook site (Fig. 3) $55 \mathrm{~m}$ west of the Morrisson site but, according to a suite of radiocarbon dates, occupied two to five centuries after the Morrisson site. Arundale's (1976) detailed analysis of the Nanook site demonstrates convincingly that it was a late spring residence, but since it is in an undrained swampy pocket in the rocks, it could have been used only when the ground was still frozen. The dwelling area, approximately $30 \mathrm{~m}$ long, was constricted by two rock outcrops $16 \mathrm{~m}$ apart. Through this space runs a single wall of laid up courses of rock and sod blocks. At intervals along this wall or bench, $1 \mathrm{~m}$ wide and $30 \mathrm{~cm}$ high, there are four clearly defined kitchen areas 
where the rocks are covered with charred fat. The fact that the single wall or bench was covered at several points by preserved caribou and seal skin suggests that this was a communal dwelling with a single, long sleeping bench divided into separate family enclosures.

In these three cases the season of use is reasonably clear but this is not the case for most of the remaining southeastern Baffin Island Dorset sites. In this region faunal analysis is less useful than it may be elsewhere for determining seasonality of occupation. Although organic preservation is good between 600 B.C. and A.D. 100, it is sporadic after this time. Furthermore, as studies of the Lake Harbour region have demonstrated (Kemp, 1976), its desirability as a hunting area comes more from the diversity and reliability of available species than from quantities of a few species. It is outside the normal seasonal range of migrating walrus and caribou, and in none of the Dorset faunal samples do migratory wild fowl appear important. Customarily in all sites, regardless of time or season, ring and other small seal species constitute $80-85 \%$ of the faunal sample, caribou $14-15 \%$, and walrus, bear, fox, and birds (predominantly guillemots) the remaining $2-3 \%$.

\section{Lithic Artifact Comparisons}

In comparing Dorset sites of several periods in this research area, lithic assemblages of 100 or more specimens invariably include the same complex of 12 artifact categories. These include: spalled burins and burin-like gravers, triangular harpoon end blades, side blades, slate knives, side-notched and stemmed chert and quartz end blades, end and side scrapers, microblades and cores, utilized flakes, and vessel fragments. None of these are specific to any part of the yearly cycle. Through time most of these categories change stylistically so that Early Dorset harpoon tips, for example, can be readily distinguished from Late Dorset ones, but variations in percentage frequencies of the various categories cannot be attributed to temporal differences (Maxwell, 1976). Similarly, changes in relative frequency of specific artifact categories at Nunguvik, North Baffin (Mary-Rousselière, 1976) do not appear to correspond with a temporal sequence.

To demonstrate patterns in the various category frequencies the simplest and most demonstrative method is that of cumulative percentages. Seven of the 12 categories that constitute the lithic component of all southeastern Baffin Dorset assemblages were selected for analysis. Utilized flakes were eliminated since these usually are casual pro tem. artifacts; microblades and cores, because the former occur in such numbers as to swamp comparisons and it is too difficult to distinguish between functional artifacts and debitage; side-notched and stemmed bifaces, since they were used both as lance tips and as knives; and side blades, because too often this category becomes a catchall for asymmetric bifaces, and because they too were used both as lance side blades and as side-hafted knives.

When the remaining seven categories - spalled burins, burin-like gravers, end and side scrapers, triangular end blades, slate knives, and vessel fragments are compared (Fig. 4), there are striking differences between the winter Morrisson site (n-1605) and the summer Crystal II one (n-585). This is particularly 


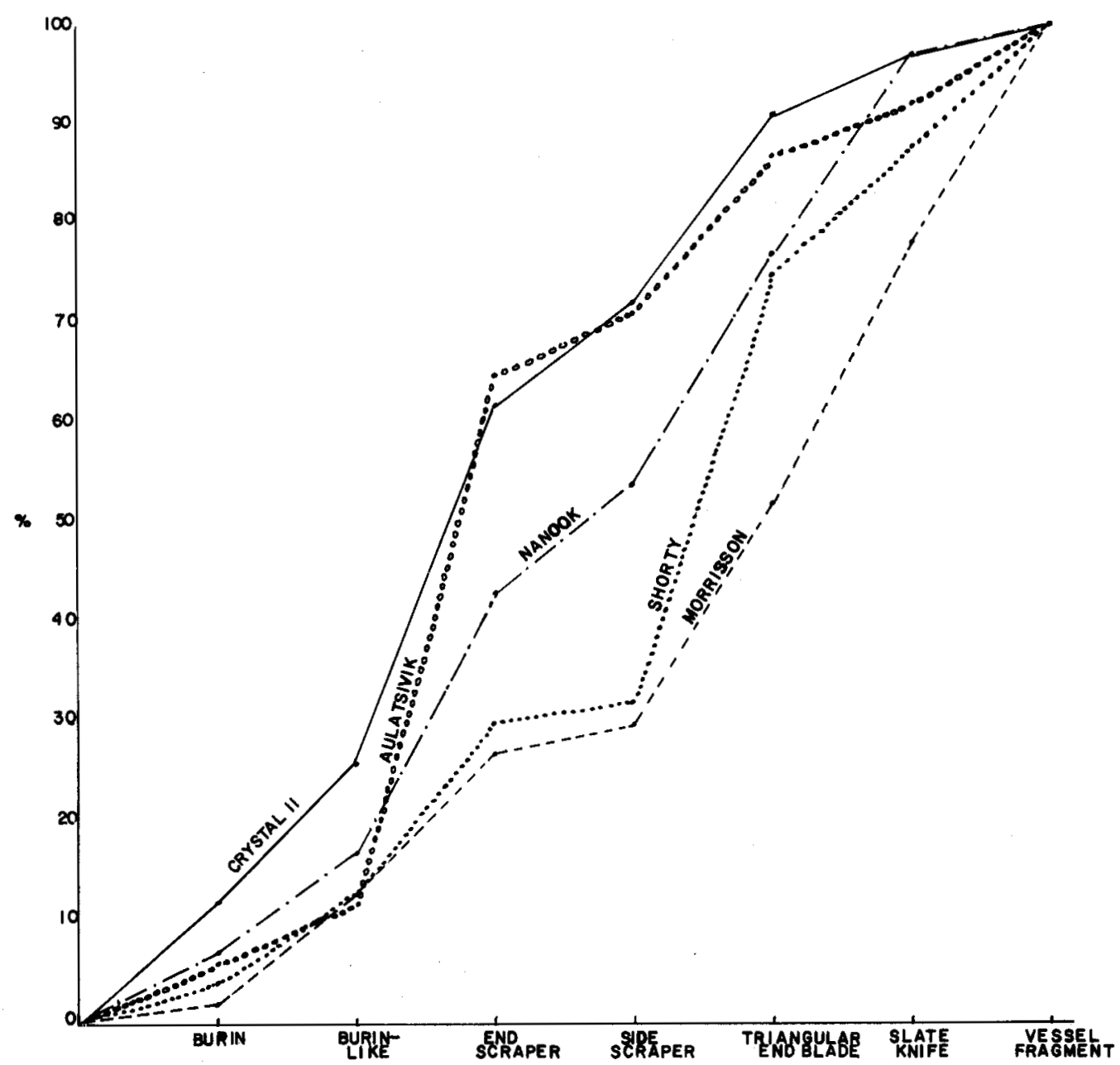

FIG. 4. Cumulative frequencies of key stone artifacts from the Crystal II (summer), Aulatsivik (summer?), Nanook (spring), Shorty (late winter-early spring), and Morrisson (winter) sites.

marked in the relative frequencies of the two types of gravers (spalled burins and burin-like tools) and the side and end scrapers. Elsewhere (Maxwell, 1974/75) I have demonstrated, through macroscopic wear analysis, tool replication, use and subsequent inspection, that these four were probably used as a set for discretely separate tasks in fashioning tools and weapons of ivory and antler.

These relative frequencies suggest higher levels of ivory and antler artifact manufacture in summer than in winter. Certain logical assumptions can be added to the empirical evidence. Finger dexterity is greater in the warmer months. The lithic raw materials are only available then, but perhaps most importantly, the frequent strong winds and drifting pack ice of summer limit time spent in hunting to a greater extent than winter storms affect sea ice hunting. 
When the relative frequencies of these same artifact categories from the Nanook site (n-1446) are compared to those of the Morrisson and Crystal II sites the slope lies between these latter two. The fact that the Nanook site artifact frequencies differ from both summer and winter groups supports the interpretation of this site as a springtime occupation and further suggests a distinctive activity set for spring as opposed to summer or winter.

The inclusion of the Shorty site (n-211) for comparison in Figure 4 may not be completely appropriate. The faunal evidence provides relatively clear indication of season of occupancy. Eighty-five percent of the animal bones come from ring seal, and of these, $92 \%$ of the seal ranged in age from neonates to pups less than one year old. Nevertheless the site represents a settlement type differing from

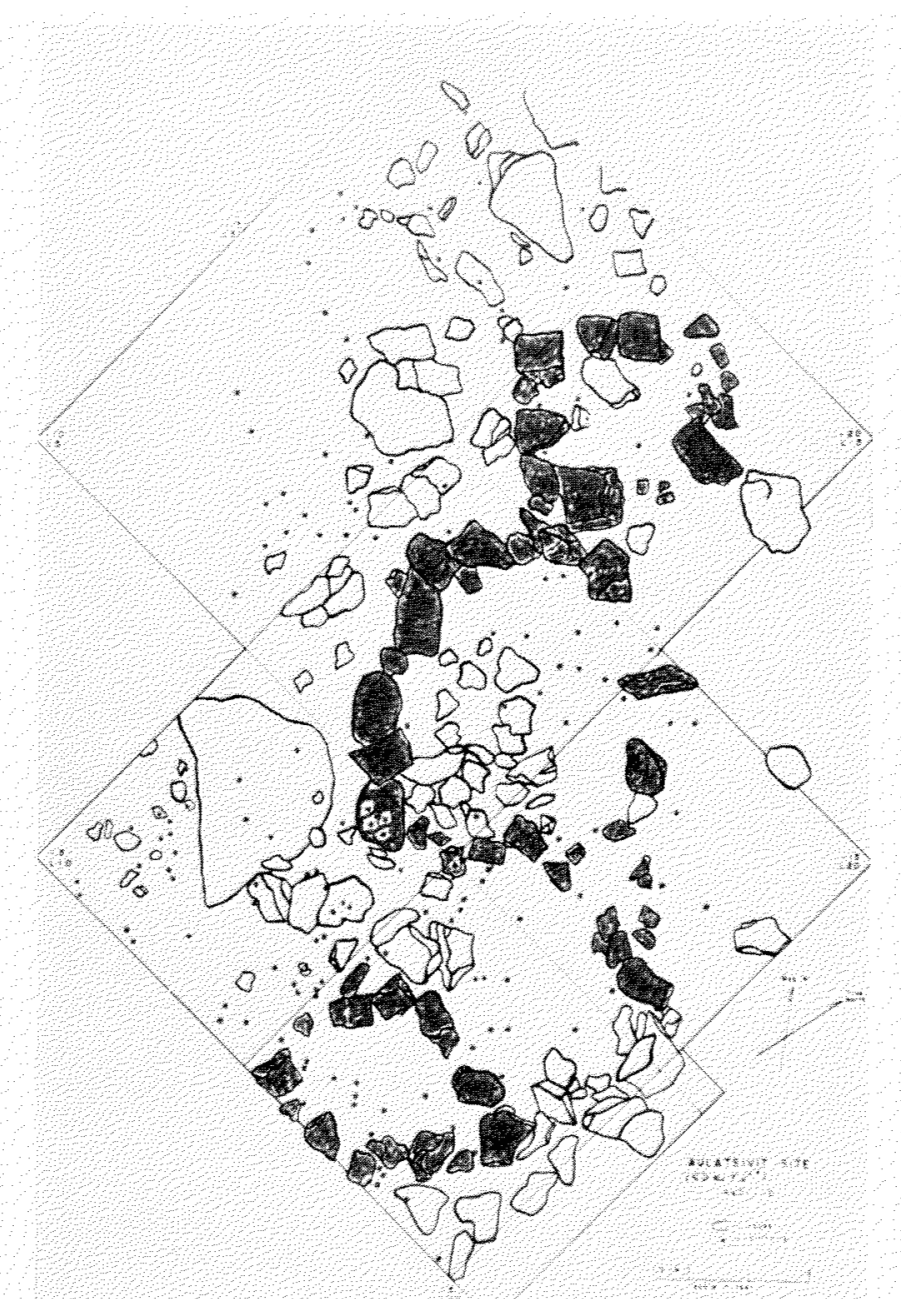

FIG. 5. Aulatsivik site (KeDr-10). Shaded rocks indicate possible internal features. 
other Dorset sites. Although much of the small locus was disturbed by a later Thule house pit, undisturbed portions demonstrated as many as 24 thin horizontal midden bands separated by layers of sterile sand, demonstrating brief but periodic use of the site. Furthermore, this clearly Late Dorset site is the only one of this later period that we have located on the outer coast, all other Late Dorset sites being located on inner bays. Consequently we interpret the site as a camp, rather than a family/band residence, used periodically in late February and March by men spending most of their time hunting young seal pups in the rough ice near shore. However, stone debitage in the site suggests that some manufacturing took place during leisure time, particularly in the shaping of harpoon end blades (and other stone tools not included in this analysis). The activities reflected in the cumulative frequencies resemble those characteristic of sets in winter settlements.

It is questionable how useful this comparison of relative frequencies might be for sites of unknown seasonality. However, the isolated structure at Aulatsivik (n-64) which appears to have been a warm weather tent platform on thin, well-drained soil (Fig. 5), had associated lithic artifacts which in relative frequencies are close to those of Crystal II. This suggests that the residence was occupied in summer, and that manufacturing activities, except for those involving use of burins and burin-like tools, were characteristic of summer work. The low frequencies of graving tools may simply be due to the small sample size.

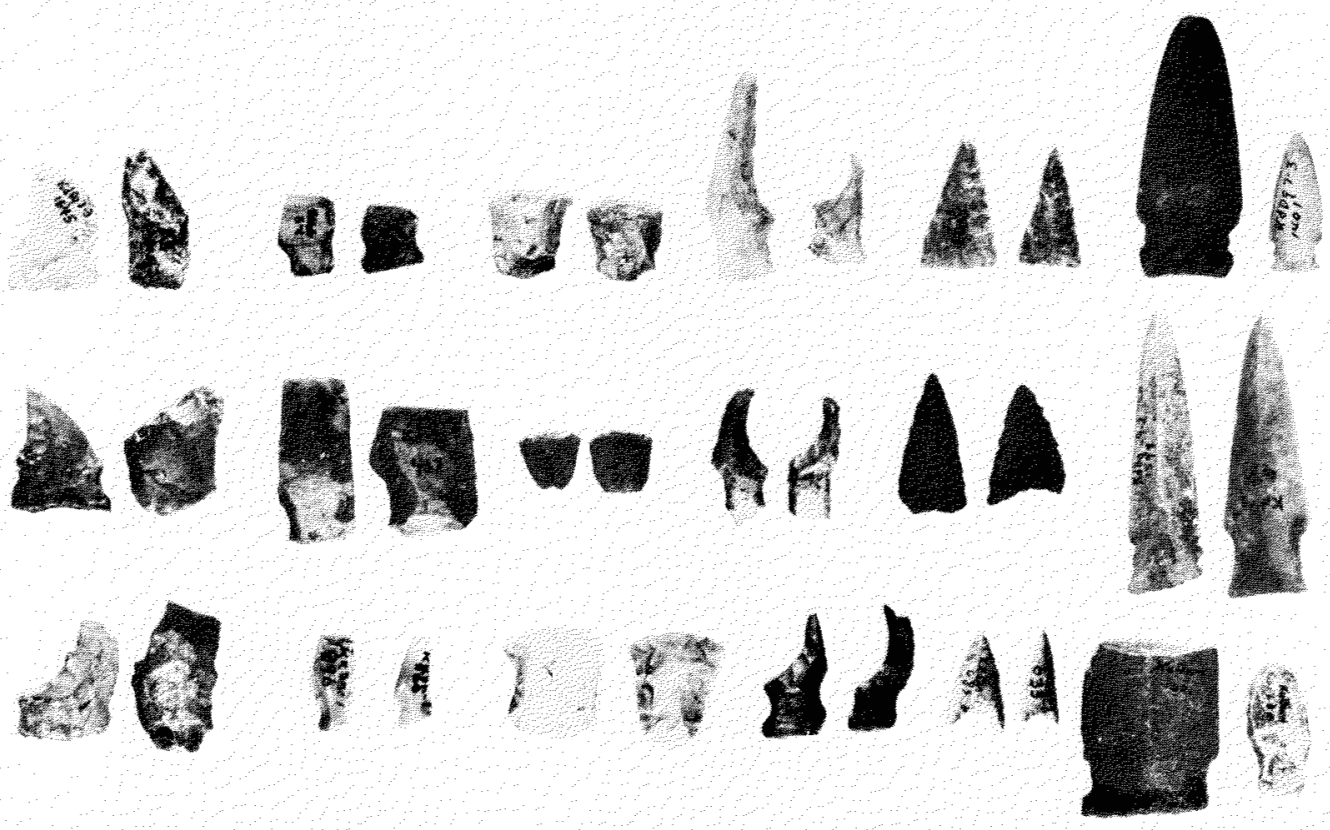

FIG. 6. Sample artifacts from the Morrisson (A), Nanook (B), and Crystal II (C) sites. From left to right, two each of spalled burins, burin-like tools, end scrapers, side scrapers, triangular end blades and slate knives. 


\section{Middle and Late Dorset Fast Ice Settlements}

When this analytic technique, combined with other independent evidence, is applied to other sites it appears that the Early Dorset sites from Cape Tanfield are the only cold season residences we have located along this southeast coast. All of the discovered Middle and Late Dorset residential type sites, then, appear to have been occupied only in the warm seasons. This leads to the conclusion that Middle and Late Dorset winter residential settlements were in snow houses on the fast ice, presumably close to the floe edge.

This may account for temporal differences in the spatial distribution of Dorset sites. In considering all of the Dorset sites we have located, the earlier ones are on exposed outer coasts, whereas later settlements are deeper in protected bays. However, if these late sites were used in winter as well as summer, their distribution appears to conflict with the evidence that the climate of Late Dorset time was much warmer than that of Early Dorset. This spatial distribution may be more reasonably explained if these late sites were only summer settlements. Undoubtedly floe edge hunting was then, as now, the most important source of food in the North Bay region. The reliability of marine food resources in this region is primarily due to a large area of fast ice and a persistent, well-defined floe edge between Big Island and Juet Island formed by a current reversal off the southeast tip of Big Island. Under present winter conditions this floe edge is only 2 to $5 \mathrm{~km}$ from land at the Morrisson site. However, because of the current reversal, as this floe edge wastes during spring it retreats from east to west rather than from south to north, putting it farther from habitable land.

If, in the later phases of Dorset development, winters were warmer than they are at present, or than they had been during Early Dorset, travel time to the floe edge, particularly with only hand-drawn sleds, could have become excessive. This problem would have been compounded by the broad band of extremely rough ice and ice cliffs which is formed between flat sea ice and shore by the extreme tidal fluctuations. A natural response to this increased travel time would have been to build on the flat ice west of the floe edge. This could also account for the distribution of summer sites after breakup since locations deep in bays would have been closer to the wasting floe edge.

\section{CONCLUSION}

A comparison of the cumulative frequencies of certain key lithic artifacts from Dorset sites on the southeastern coast of Baffin Island indicates different sets of tool-making activities. An earlier analysis of relative frequencies (Maxwell, 1976) had indicated that these differences were not due to cultural change through time. The fact that these differences appear to co-occur with differences in residence structures differentially occupied in winter, spring, and summer suggests at least three seasonally differing sets of tool-making activities. Applying the same technique to other Dorset sites in the North Bay region (Maxwell, n.d.) indicates the probability that the Middle and Late Dorset sites we have located are all summer settlements. This leads to the conclusion that the warming trend of this later period resulted in such increased travel time in 
hunting that winter settlements were moved to the floe edge of the fast ice. This, in turn, may explain the location of Middle and Late Dorset summer settlements deep in protected bays.

It does not necessarily follow that the pattern of manufacturing activities we have seen in southeastern Baffin would be applicable in other regions. However, we note that on northern Baffin Island, evidence from House 46 at Nunguvik reflects a similar pattern (Mary-Rousselière, 1979:65). In this house an unusually large quantity of caribou bones, implying late summer-early fall hunting, is associated with $6 \%$ spalled burins in the lithic assemblage.

This study does underline a need for considering differential seasonal activities when inter-site comparisons are made. It becomes increasingly clear that the apparent variance between southeastern Baffin lithic tool development and that in other Dorset sites is partly a function of improper comparisons. In several regions where Dorset sites have been located, house pits have been clearly evident from the surface (Cf. Mary-Rousselière, 1979:65). In other parts of the Arctic, vertical slabs of axial features often penetrate the surface. If these two variants are winter dwellings and are more often selected for excavation than less obvious summer sites, and if throughout the Dorset sphere there has been the seasonal differentiation in manufacturing activities which we find on southeastern Baffin, then comparisons between warm and cold season sites would be inappropriate. This could explain both the very close similarity between cultural assemblages from the Early Dorset winter settlements on Cape Tanfield and those of Igloolik winter sites, and also the discrepancies between lithic assemblages from Late Dorset winter settlements at Igloolik and Late Dorset summer ones on southeastern Baffin Island. 


\section{ACKNOWLEDGEMENTS}

The National Science Foundation supported the research on which this paper is based.

\section{REFERENCES}

ARUNDALE, W. H. 1976. The archaeology of the Nanook Site: an explanatory approach. Ph.D. Dissertation, Dept. of Anthropology, Michigan State Univ., East Lansing, Mich.

COX, S. L. 1978. Palaeo-Eskimo occupations of the North Labrador Coast. Arctic Anthropology 15 (2): 96-118.

HARP, E. Jr. 1976. Dorset settlement patterns in Newfoundland and southeastern Hudson Bay. Memoirs of the Society for American Archaeology 31: 119-138.

KEMP, W. B. 1976. Inuit land use in south and east Baffin Island. In: Freeman, M.M.R. (ed.). Inuit Land Use and Occupancy Project Report, vol. 1. Ottawa: Dept. of Indian and Northern Affairs. 125-151.

MARY-ROUSSELIÈRE, G. 1976. The Paleoeskimo in northern Baffinland. Memoirs of the Society for American Archaeology 31: 40-57.

1979. The Thule culture on North Baffin Island: early Thule characteristics and the survival of the Thule tradition. In: McCartney, A.P. (ed.). Thule Eskimo Culture: An Anthropological Retrospective. Archaeological Survey of Canada, Paper 88. 54-75.

MAXWELL, M. S. 1974/75. An Early Dorset harpoon complex. Folk 16-17: 125-132.

1976. Pre-Dorset and Dorset artifacts: the view from Lake Harbour. Memoirs of the Society for American Archaeology 31: 58-78.

1979. The Lake Harbour region: ecological equilibrium in sea coast adaptation. In: McCartney, A.P. (ed.). Thule Eskimo Culture: An Anthropological Retrospective. Archaeological Survey of Canada, Paper 88. 76-88.

n.d. Dorset site reports: southeastern Baffin Island. Manuscript.

PLUMET, P. 1976. Archéologie du Nouveau-Québec: habitats Paléo-Esquimaux à Poste-de-laBaleine. Le Centre d-Études Nordiques de l'Université Laval. 7.

1979. Thuleens et Dorsetiens dans l'Ungava (Nouveau Québec). In: McCartney, A.P. (ed.). Thule Eskimo Culture: An Anthropological Retrospective. Archaeological Survey of Canada, Paper 88. 110-121.

ROWLEY, G. 1940. The Dorset culture of the Eastern Arctic. American Anthropologist 42: 490-499.

SCHLEDERMANN, P. 1978. Preliminary results of archaeological investigations in the Bache peninsula region, Ellesmere Island, N.W.T. Arctic 31 (4): 459-474.

WENZEL, G. 1979. Analysis of a Dorset-Thule structure from northwestern Hudson Bay. In: McCartney, A.P. (ed.). Thule Eskimo Culture: An Anthropological Retrospective. Archaeological Survey of Canada, Paper 88. 122-133. 